\title{
Integration of Information Technology and Traditional Taekwondo Curriculum
}

\author{
Yuqing Guo*, Daqing Wang and Xiuli Cheng \\ Institute of Educational Technology, College of Education, Zhejiang University, \\ Hangzhou, China.310008 \\ jasminee1@126.com
}

\begin{abstract}
The use of information technology in education has been an issue of common concern of educators in the 21st century. The integration of information technology and curriculum is therefore a hot research area and a large amount of research outcomes have been achieved in recent years, including many educational reforms and demonstrative projects carried in $K$ 12 schools and universities. Comparatively, the use of information technology in physical education is very rare. Taking the Taekwondo curriculum of Zhejiang University as a case, the research utilizes Sakai, an open learning platform to assist the physical education, applying questionnaire and reviewing method. Results show that web-based teaching platforms play a significant role in improving teaching efficiency.
\end{abstract}

Keywords: information technology, the integration of information technology and curriculum, physical education, Taekwondo

\section{Introduction}

Information and Communication Technologies (ICTs) have been widely applied in various subjects in all kinds of school systems around the world. Technology enhanced learning is a research field that has matured considerably over the last decades. The study of the effectiveness of the use of technology in physical education has already attracted researcher's interest to a great extent. An increased number of scientific journals are publishing on this topic [1].

International Journal of u- and e- Service, Science and Technology Many researchers are experimenting on the development and application of visual teaching tools, digital multimedia and virtual learning environments for the teaching of motor skills [2-6]. But literature review found there are rare successful instructional cases of integrating information technology into physical education currently and the reasons include but not limit to the lack of incentive systems, the scarcity of software and hardware appliance, time constraints, etc.

Results of The British Committee for Education Standards' investigation found that lack of application of information technology in physical education was a weak link for the development of the subject. Although the importance of the integration of information technology and core curriculums is highly emphasized by institutes of British education communication and technology, the utilization of ICTs in physical education is still a controversial issue. According to the British Committee for Curriculum Standards, opportunities should be provided for students to use information technology in their study. 
The research of Dr. Dillman, professor of the Economic and Social Science Center in Washington State University shows that $92 \%$ of physical education teachers hold positive attitude toward the application of information technology in physical education, and $88 \%$ of the institute of physical education apply CD players in their dance classes or other physical education classes. The software Dart Fish is advocated to use in physical education classes in Devon, Britain, with the purpose to film the classroom in real time and provide feedbacks to students timely [7]. Information technology is widely used in the East Midlands and northwestern of the Great Britain.

The structure of a physical education lesson is undoubtedly multidimensional. Instructors need to demonstrate skills with the description of the rules and principles. Learner needs to practice movement type activities and cognitive tests. In order to serve both the instructors' and learners' needs, researchers suggest the combinational use of text, images, animation, sound and video in the same multimedia application, which in the majority of cases is a computer learning environment [8].

In basketball, Vernadakis, Zetou, Tsitskari, Giannousi \& Kioumourtzoglou applied specially designed software for the teaching of the rules and the ball-shooting skill [6]. In the frame of Katona's research [9], an interactive e-book was used for the purposes of the university course "Sport recreation, Leisure time sports theory and practice I and II" of the Faculty of Pedagogy in the University of West Hungary. Specific sport skills of team invasion games were taught in a research by Hastie, Casey, and Tarter [5] on a server software online database named "wiki". Libkuman et al [10] and sommer, \& Ronqvist [11] tested, in separate studies, the effects of training golf athletes with the use of interactive software on their accuracy to shoot on target. As for the application of teaching auxiliary platform in physical education, researchers also used Blog to promote students' knowledge construct with remarkable results [12].

There are more successful attempts in the application of information technology in dance classes. Many dance course websites were developed to satisfy the need for distance education and lifelong learning [13-15]. The majority of the published research concentrated on the development of software or on the design of interactive learning platforms, without assessing their influence on dance performance in real time [16].

Multimedia educational resource is one of the important technologies in computer assisted instruction. It does not require expert knowledge in computer skills. Learning management system can organize all types of resource (i.e., text, image, sound, graphics, etc.,) of the course and provide a learning environment for students to regulate his/her own learning stages and determine those that fit with his/her learning style. Learners can choose personalized learning styles and control their learning process by themselves [8]. In total, the utilization of information technology may promote instruction quality, collaboration, interaction and more personalized feedback $[14,17]$. Researchers of the last ten years that have used multimedia resources to assist motor performance and dance education, but there is no related research has been found in Taekwondo education in university.

The purpose of this study is to explore an effective way of integrating information technology into Taekwondo course by using Sakai, an open source learning platform, into a Taekwondo Course. The course is an elective course and its target students are undergraduate students majoring in sports majors. The focus of traditional Taekwondo course is the explanation and excise of skills, while the cultural heritage of Taekwondo is often ignored. Generally speaking, the traditional teaching method, which is featured by teacher's explanation and demonstration and student's follow-up practice, is the major obstacle of the Taekwondo culture instruction. 


\section{Research Process}

\subsection{Introduction}

Research on Sakai has been conducted for many years in the Modern Educational Technology Center of Zhejiang University and substantial results have been achieved. The platform has been applied in some undergraduate and graduate courses in past several years. As a free and open web-based learning environment, Sakai is mainly utilized in teaching, research work and collaboration. Similar with Moodle, Sakai is a course management system and a virtual learning environment. It has been applied as teaching assistant platform of graduate course in College of Education of Zhejiang University for several years, but it has not yet applied in Taekwondo course.

A course site was developed in Sakai to assist Taekwondo course (see Figure 1). The platform tools include course notification, calendar, syllabus, course resources. Multimedia learning content was developed which includes basic knowledge of Taekwondo, poomsae tai$\mathrm{ji}$, teaching videos of leg skills, combat videos and exciting games and performances.

The course site mainly consists of syllabus, schedule, curriculum resources, forum and other parts. In curriculum resource part, there are five modules for students to learn Taekwondo: the basic knowledge of Taekwondo, poomsae tai-ji, teaching videos of leg skills, combat videos and exciting games and performances (Table. 1).

Table 1. Content Design of the Course Site

\begin{tabular}{llccc}
\hline & \multicolumn{1}{c}{ Content } & \multicolumn{3}{c}{ Resources formats } \\
\cline { 3 - 5 } & texts & Pictures & Videos \\
\hline 1、 & Basic knowledge of Taekwondo & $\sqrt{ }$ & $\sqrt{ }$ & \\
2、 Poomsae tai-ji & $\sqrt{ }$ & $\sqrt{ }$ & $\sqrt{ }$ \\
3、 Teaching videos of leg skills & $\sqrt{ }$ & $\sqrt{ }$ & $\sqrt{ }$ \\
4、 Combat videos & & & $\sqrt{ }$ \\
5、 Exciting games and performances & & & \\
\hline
\end{tabular}

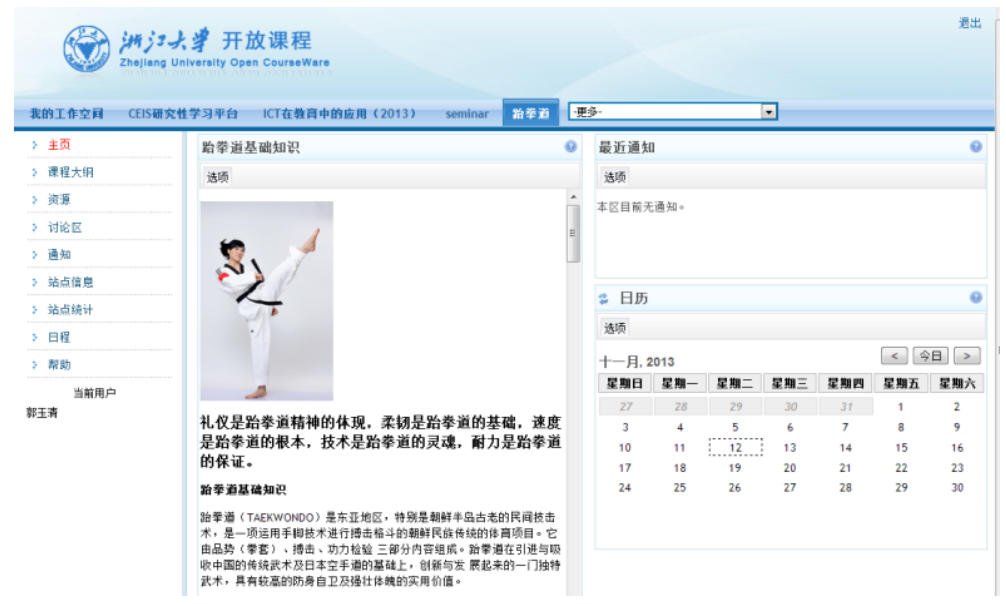

Figure 1. The Homepage of Taekwondo Course

\subsection{Objectives}

The overall objective of this research is to assess to which extent the platform helps students in learning Taekwondo. Data were collected to identify the usefulness of the platform and performance of learners. 


\subsection{Tasks}

Before the class, course website was established in Sakai, and learning resources were created by instructors and teaching assistants. At the beginning of the Taekwondo course, the website was introduced to learners in the two experimental classes.

1 Face to face lessons in all classes with the same instruction design.

2 Learners were encouraged to do Self-Regulated learning in experimental classes; multimedia contents were given in Sakai platform.

3 Learners were encouraged to do Self-Regulated learning in traditional classes by using online open content, but there is no platforms provided.

\subsection{Data collection}

A site statistics tool in Sakai was used to collect participant action, capturing access and visit activates. Participants were asked to complete a questionnaire after the semester to collect qualitative feedback about the perceived usefulness, advantage and potential drawbacks.

\section{Analysis}

\subsection{Demographics}

The research was conducted in the spring and summer semester in 2013 at Zhejiang University. Participants of the research were freshmen and sophomores of four classes randomly selected from Taekwondo class. Two classes were randomly selected from the four classes as experimental classes. Blended learning model which integrating Sakai into Taekwondo teaching was utilized in experimental classes while the two control classes still applied traditional teaching method.

Table 2. Participants' Demographics

\begin{tabular}{cccccc}
\hline \multicolumn{7}{c}{ 1. } & The whole participants & & & \\
\hline Male & Female & Freshman & Sophomore & Others & Total \\
\hline 73 & 115 & 104 & 82 & 2 & 188 \\
\hline $\mathbf{2 .}$ & Participants using Sakai & & & \\
\hline Male & Female & Freshman & Sophomore & Others & Total \\
\hline 39 & 54 & 49 & 43 & 1 & 93 \\
\hline 3. & Participants applying traditional teaching method & & \\
\hline Male & Female & Freshman & Sophomore & Others & Total \\
\hline 34 & 61 & 55 & 39 & 1 & 95 \\
\hline
\end{tabular}

There were 188 students participating in the study, including 93 of which belonged to experimental classes and the other 95 were in traditional classes. Most of the participants were freshman and sophomore (see Table 2). Teaching results were obtained from the comparison of two experimental classes and the other two traditional classes.

From the data collected by Sakai statistics tool, the most popular tool in the learning platform is "Resource". Percentage of this tool's visiting reached $81.90 \%$, the second popular tool is syllabus (see Table 3 and Figure 2). Since participants have face to face class every week, it is not necessary to get notification online. Even instructor will publish news to clear learning resources updates, but participants prefer to visited resource tool directly. 
Table 2. Tools Visited by Learners

\begin{tabular}{|c|c|}
\hline Tools & Percentage of Visiting \\
\hline Notification & $0.05 \%$ \\
\hline Calendar & $0.40 \%$ \\
\hline Site Information & $0.65 \%$ \\
\hline Site Statistics & $0.70 \%$ \\
\hline Syllabus & $16.30 \%$ \\
\hline \multirow[t]{7}{*}{ Resource } & $81.90 \%$ \\
\hline & Notification \\
\hline & - Calendar \\
\hline & Site Information \\
\hline & Site Statistics \\
\hline & Syllabus \\
\hline & Resource \\
\hline
\end{tabular}

Figure 2. Tools Visited by Learners

Among the online learning resources, combat videos were most visited, followed by basic knowledge of Taekwondo, Poomsae tai-ji, which is extracurricular expanding content for the Taekwondo amateur, exciting games and performances, and teaching videos of leg skills (Table 4 and Figure 3).

Table 3 Learning resource visited by learners

\begin{tabular}{|c|c|}
\hline Learning Resource & Percentage of Visited \\
\hline Basic Knowledge & $25 \%$ \\
\hline Poomsae tai-ji & $16 \%$ \\
\hline Teaching videos of leg skills & $14 \%$ \\
\hline Combat videos & $29 \%$ \\
\hline \multirow[t]{5}{*}{$\underline{\text { Exciting games and performances }}$} & $16 \%$ \\
\hline & Basic Knowledge \\
\hline & Poomsae tai-ji \\
\hline & $\begin{array}{l}\text { Teaching videos of } \\
\text { leg skills }\end{array}$ \\
\hline & - Combat videos \\
\hline
\end{tabular}

Figure 3. Learning Resource Visited by Learners 


\subsection{Data Analysis}

25 students were selected randomly from experimental classes to be interviewed after the course. The results showed that, $85 \%$ of the interviewees thought that the Taekwondo course assisted by Sakai was very effective while only $15 \%$ think the result is not obvious. As to the content design of the site, $75 \%$ of the interviewees were satisfied with it while the other $25 \%$ thought it was not very novelty.

Table 5. Test Results of Independent Samples Test

\begin{tabular}{|c|c|c|c|c|c|c|c|c|c|c|}
\hline & & $\begin{array}{r}\text { Leven } \\
\text { var } \\
\text { equ }\end{array}$ & $\begin{array}{l}\text { est of } \\
\text { ice } \\
\text { ons }\end{array}$ & & & & est of me & n equations & & \\
\hline & & $\mathrm{F}$ & Sig. & $\mathrm{t}$ & df & Sig & $\mathrm{D}$ & Std.Error & $\begin{array}{r}95 \% \mathrm{C} \\
\text { inte } \\
\text { dif } \\
\end{array}$ & $\begin{array}{l}\text { idence } \\
\text { ls of } \\
\text { nce }\end{array}$ \\
\hline & & & & & & & & & Lower & Upper \\
\hline $\mathrm{T}$ & $\begin{array}{c}\text { Variances } \\
\text { assumed } \\
\text { equal }\end{array}$ & 1.633 & .202 & 1.50 & 263 & .134 & 1.7035 & 1.1337 & -.5287 & 3.935 \\
\hline 1 & $\begin{array}{c}\text { Variances } \\
\text { assumed } \\
\text { unequal }\end{array}$ & & & 2.45 & 244.53 & .015 & 1.7035 & 6929 & .3385 & 3.068 \\
\hline
\end{tabular}

About $50 \%$ of the interviewees commented that the videos of poomsae were helpful for their learning interests while others thought the videos of exciting games were more attractive; about $70 \%$ thought they were inspired to gather more information about Taekwondo on the Internet by the assistance of Sakai.

About $90 \%$ of the interviewees logged in the site once a week on average. 50\% reported that time constraints was the main obstacle of using the site as there were too many selective courses for freshmen and sophomores to learn. Too much homework occupies their spare time.

As Table 5 shows, the differences of performance between experimental classes and control classes are significant. The academic records of the former are much better than that of the latter.

\subsection{Summary}

The effects of Sakai on Taekwondo course are summarized through interviews and data analysis.

1. Students' learning interests in Taekwondo are greatly improved through the application of Sakai. There are little time for students to learn the culture and history of Taekwondo in traditional classroom. Students' learning interests of Taekwondo are thus hard to arouse. The utilization of Sakai, however, provides a platform to introduce exciting videos of international games, players' interviews, the culture of Taekwondo, etc., to students. The Taekwondo learning situation created is infectious for them to get a comprehensive and deeper understanding about the sport.

2. Sakai plays an important role in promoting teaching efficiency. The videos and animations of essentials of motion and skills of Taekwondo on Sakai are effective supplements to teachers' explanation and demonstration. 
3. Sakai acts as a culture carrier of Taekwondo. The practicing of essentials of motion and promoting of physical quality are the main focuses of traditional Taekwondo classroom. The culture of the sport is usually ignored. The application of Sakai provides a good way to solve the problem. Large amount of supplementary materials such as videos, audios, pictures about Taekwondo on the internet can be gathered on the platform. Courseware focusing on the culture and history of Taekwondo can thus be made by analyzing and organizing these materials. It provides a good way for students to get a more comprehensive understanding of Taekwondo and the culture of it be inherited at the same time.

4. Sakai provides a platform for the communication between students and teachers.

\section{Conclusion and Future Work}

\subsection{Conclusion}

In this article, we presented a study to identify whether ICT can improve physical education course in university by taking the Taekwondo curriculum of Zhejiang University as a case. A learning platform was developed in Sakai, which provides educational resources including basic knowledge of Taekwondo, Poomsae tai-ji, leg skills and combat videos, etc., the formats of resources include video, photo and text. The platform also provides communication tools like Wiki and Discussion board to encourage students' cooperative activities. Research results were obtained from the comparison of two experimental classes and the other two control classes, 188 students participated in this study, 95 of which took traditional Taekwondo curriculum and the other 93 took ICT supported Taekwondo curriculum. The data analysis showed that the integration of information technology into physical education has positive effects on teaching efficiency.

The contribution of the article is two-folds. Firstly, we have demonstrated that the existing eLearning findings and experiments from other discipline can also be used in a meaningful way to support physical education course. Both teachers with background knowledge in learning platform as well as teachers with no background knowledge and skills in learning platform indicate that the platform helped them in management learning content and teaching Taekwondo culture. In addition, they feel more confident using Sakai when necessary supports are provided by experts.

Secondly, it was found that video and photo type of resources are more popular for learners after comparing the visit times of different types of learning resources. Combat videos are the favorite content for its competitiveness and entertainment. Communication tools are not wildly used. The reasons of which line in two aspects: most of the collaboration occurs in class and the lack of time to login.

\subsection{Future Work}

In this article, we presented a study to identify whether ICT can improve physical education course in university by taking the Taekwondo curriculum of Zhejiang University as a case. A learning platform was developed in Sakai, which provides educational resources including basic knowledge of Taekwondo, Poomsae tai-ji, leg skills and combat videos, etc., the formats of resources include video, photo and text. The platform also provides communication tools like Wiki and Discussion board to encourage students' cooperative activities. Research results were obtained from the comparison of two experimental classes and the other two control classes, 188 students participated in this study, 95 of which took traditional Taekwondo curriculum and the other 93 took ICT supported Taekwondo 
curriculum. The data analysis showed that the integration of information technology into physical education has positive effects on teaching efficiency.

The contribution of the article is two-folds. Firstly, we have demonstrated that the existing eLearning findings and experiments from other discipline can also be used in a meaningful way to support physical education course. Both teachers with background knowledge in learning platform as well as teachers with no background knowledge and skills in learning platform indicate that the platform helped them in management learning content and teaching Taekwondo culture. In addition, they feel more confident using Sakai when necessary supports are provided by experts.

Secondly, it was found that video and photo type of resources are more popular for learners after comparing the visit times of different types of learning resources. Combat videos are the favorite content for its competitiveness and entertainment. Communication tools are not wildly used. The reasons of which line in two aspects: most of the collaboration occurs in class and the lack of time to login.

\section{Acknowledgements}

This research was supported by the Fundamental Research Funds for the Central Universities, and also supported by Zhejiang Education Science project "Integration of Information Technology and Traditional Taekwondo Curriculum" (SCG402).

\section{References}

[1] R. Sorrentino, "A Simulation of Internet Enhanced Motor Learning", Phd thesis, University of Calgary, Canada, (2000).

[2] A. Amaradidis, P. Antoniou and I. Giossos, "Distance education as solution in adult education for female physical education teachers", In A. Mendez-Vilas, A. Solano Martin, J. A. Mesa Gonzalez \& J. Mesa Gonzalez (Eds.), Current Developments in Technology-Assisted Education. Badajoz, Spain: Formatex, (2006), pp. 386-390.

[3] D. Goulimaris, M. Koutsouba and Y. Giosos, "Organization of a distance postgraduate dance program and the participation of students specializing in dance", Turkish Online Journal of Distance Education, vol. 3, no. 9, (2008), pp. 59-73.

[4] G. Katona, "The use of digital materials for instruction in sport topics at the University of West Hungary", International Journal of Education and Development using Information and Communication Technology, vol. 3, no. 1, (2007), pp. 126-133.

[5] P. A. Hastie, A. Casey and A. M. Tarter, "A case study of wikis and student designed games in physical education”, Technology, Pedagogy and Education, vol. 1, no. 19, (2010), pp. 79-91.

[6] P. Nagarajan and G. W. Jiji, "Online Education System (e- learning)", International Journal of u- and eService, Science and Technology, vol. 3, no. 4, (2010) December, pp. 37-48.

[7] A, Thomas and G, Stratton, "What we are really doing with ICT in physical education: a national audit of equipment, use, teacher attitudes, support, and training", British Journal of Educational Technology, vol. 4, no. 37, (2006), pp. 617-632.

[8] A. Dania, D. Hatziharistos, M. Koutsouba and V. Tyrovola, "The use of technology in movement and dance education: Recent practices and future perspectives", Procedia-Social and Behavioral Sciences, vol. 15, (2011), pp. 3355-3361.

[9] G. Katona, "The use of digital materials for instruction in sport topics at the University of West Hungary", International Journal of Education and Development using Information and Communication Technology, vol. 1, no. 3, (2007), pp. 126-133.

[10] T. M. Libkuman, H. Otani and J. Steger, "Training in timing improves accuracy in golf", The Journal of General Psychology, vol. 129, (2002), pp. 17-20.

[11] M. Sommer and L. Rönnqvist, "Improved motor-timing: effects of synchronized metronome training on golf shot accuracy", Journal of Sports Science and Medicine, vol. 8, (2009), pp. 648-656.

[12] M. Papastergiou, V. Gerodimos and P. Antoniou, "Multimedia blogging in physical education: Effects on student knowledge and ICT self-efficacy", Computers \& Education, vol. 3, no. 57, (2011), pp. 1998-2010. 
[13] Y. Giosos, E. Mavroeidis and I. M. Koutsouba, "Research in distance education: review and perspectives", Open Education - The Journal for Open and Distance Education and Educational Technology, vol. 1, no. 4, (2008).

[14] Ä. Leijen, W. Admiraal, L. Wildschut and P. R.-J. Simons, "Students' Perspectives on E-learning and the Use of a Virtual Learning Environment in Dance Education”, Research in Dance Education, vol. 2, no. 9, (2008), pp. 147-162.

[15] A. Damianakis, E. Tsadima and D. Tsatsos, "Open Dance: A program for learning traditional dances with the use of distance education learning tools", In P. Politis (Eds.) Proceedings of the 1st Educational Congress "Incorporation and use of ICT in the educational process", Volos, Greece (in Greek), (2009).

[16] D. Risner and J. Anderson, "Digital Dance Literacy: An Integrated Dance Technology Curriculum Pilot Project”, Research in Dance Education, vol. 2, no. 9, (2008), pp. 111-126.

[17] K. W. Lai, "ICT supporting the learning process: The premise, reality, and promise", In International Handbook of Information Technology in Primary and Secondary Education, Springer US, (2008), pp. 215230.

\section{Authors}

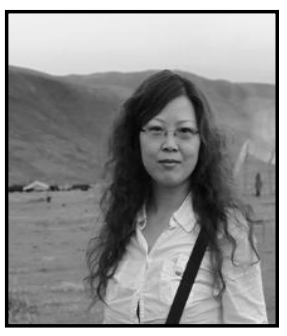

Niki Yuqing Guo, she is an assistant professor working at the Institute of Educational Technology, College of Education, Zhejiang University. Her research interests include social computing, educational data mining, and social nature of online learning in SAKAI, etc.

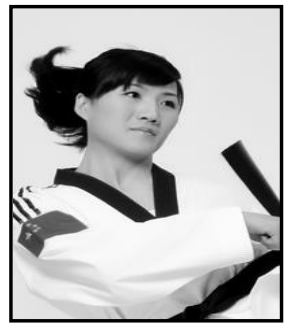

Daqing Wang, she is an assistant professor teaching Taekwondo at Department of Public Physical Education and Arts, Zhejiang University. Her research interests mainly involve teaching reform of physical education curriculum, the integration of information technology and physical education curriculum, etc.

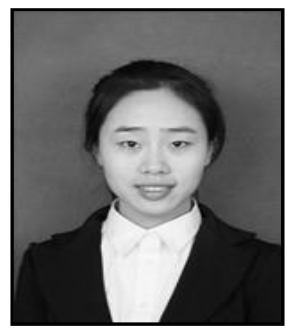

Xiuli Cheng, she is a graduate and teaching assistant of the Institute of Educational Technology, College of Education, Zhejiang University. Her research interests mainly include e-learning, educational data mining, integration of information technology and curriculum. 
International Journal of $u$ - and e- Service, Science and Technology Vol.7, No.3 (2014) 